\title{
Primary pulmonary hypertension of unusually long duration
}

\author{
A. D. Charters and W. de C. Baker \\ From Sir Charles Gairdner Hospital, Perth, Western Australia; \\ and Prince Henry Hospital and Prince of Wales Hospital, N.S.W., Australia
}

Primary pulmonary hypertension in a male patient began at the age of 6, and he died at 25, after a course of 19 years. No previous report of such a long course has been found.

A congenital rather than a thrombotic cause is supported by the onset in a boy, the absence of breathlessness on exertion until his last few years, and the medial hypertrophy of the arterioles, without evidence of organic obstruction.

Long intervals, up to 12 years, occurred without symptoms, and there was lack of constancy of the degree of effort required to produce syncope. It is suggested that these features resulted from a large reflex factor, in view of the absence of any great rise of pulmonary artery pressure on catheterization.

Primary pulmonary hypertension is not so uncommon as was previously thought, or it is increasing in frequency. Wood (1956) recorded an incidence of $0 \cdot 17$ per cent among his patients with cardiovascular disease, and Fleming (1960) reported 8 patients in one year in Sydney. This case may be of interest because of its long duration, the onset of symptoms in a boy aged 6 , the long intervals without symptoms, and inconstancy between the degrees of exertion and attacks of syncope.

\section{Case Report}

The patient, a European in Kenya, was 24 when first seen in June 1955. There was no family history of cardiac or other disease. He had one brother who was well. His symptoms began at 6 years when he used to faint for some seconds on exerting himself at games. Attacks persisted for 6 months, after which he was free from them for 12 years. They then recurred about once in two months but not consistently, for sometimes he could carry out physical exertion without attacks. His episodes again diminished in frequency, though occasional attacks continued until 2I, when they became more frequent and then gradually got worse and he had to discontinue playing games. He was more liable to attacks when exerting himself on a full stomach or walking fast uphill without 'getting previously warmed up'. $\mathrm{He}$ never passed urine or bit his tongue during attacks, though he sometimes bruised or cut his head and once fell and broke a tooth. His unconsciousness lasted up to a minute.

He sometimes had minor attacks of tightness, but not pain, in the lower part of his chest, warning signs that he would faint if he continued his exertion. He also experienced slight breathlessness and sweating before attacks and was stated to go a grey colour. If he sat down when these symptoms developed they gradually passed away in three or four minutes. He had no breathlessness on exertion until his last few years, and no swelling of his feet or cough. He was observed to have bradycardia during attacks, and a trained nurse found his pulse rate 130 immediately after one. Apart from his syncope his general health was good. He did not smoke.

On examination in 1955, aged 24 , he looked healthy. No cyanosis, clubbing, or dyspnoea at rest. Slight venous congestion of cervical veins with prominent a waves, but no oedema or enlargement of his liver. Pulse was 80 , regular, and of somewhat small volume. Blood pressure was I $6 / 84 \mathrm{~mm}$. Hg. Cardiac impulse was a right ventricular thrust, both visible and palpable, the left limit being in the fifth left interspace $0.6 \mathrm{~cm}$. inside the midclavicular line. Pulmonary second sound was accentuated and split and coinciding with a palpable shock. Aortic second sound was faint. No murmurs were heard. No abnormality was found in lungs, abdomen, or nervous system.

Electrocardiogram in 1955 (Fig. r) showed right atrial hypertrophy and conspicuous right ventricular hypertrophy and ischaemia. Tracings is months later showed larger $P$ waves and $R$ waves in the right praecordial leads, and more deeply inverted T waves, particularly in V6. Chest $x$-rays (Fig. 2) in March 1953, June 1955, and September I956 showed progressive cardiac enlargement. Dr. W. G. S. Hopkirk reported in 1956, 'frontal area of heart grossly increased. Aortic knuckle inconspicuous. Pulmonary arc grossly convex and separated from ventricular border by a shallow concavity. Ventricular border grossly out to the left. Only slightly increased prominence of lower right border. Left ventricle little if at all enlarged 


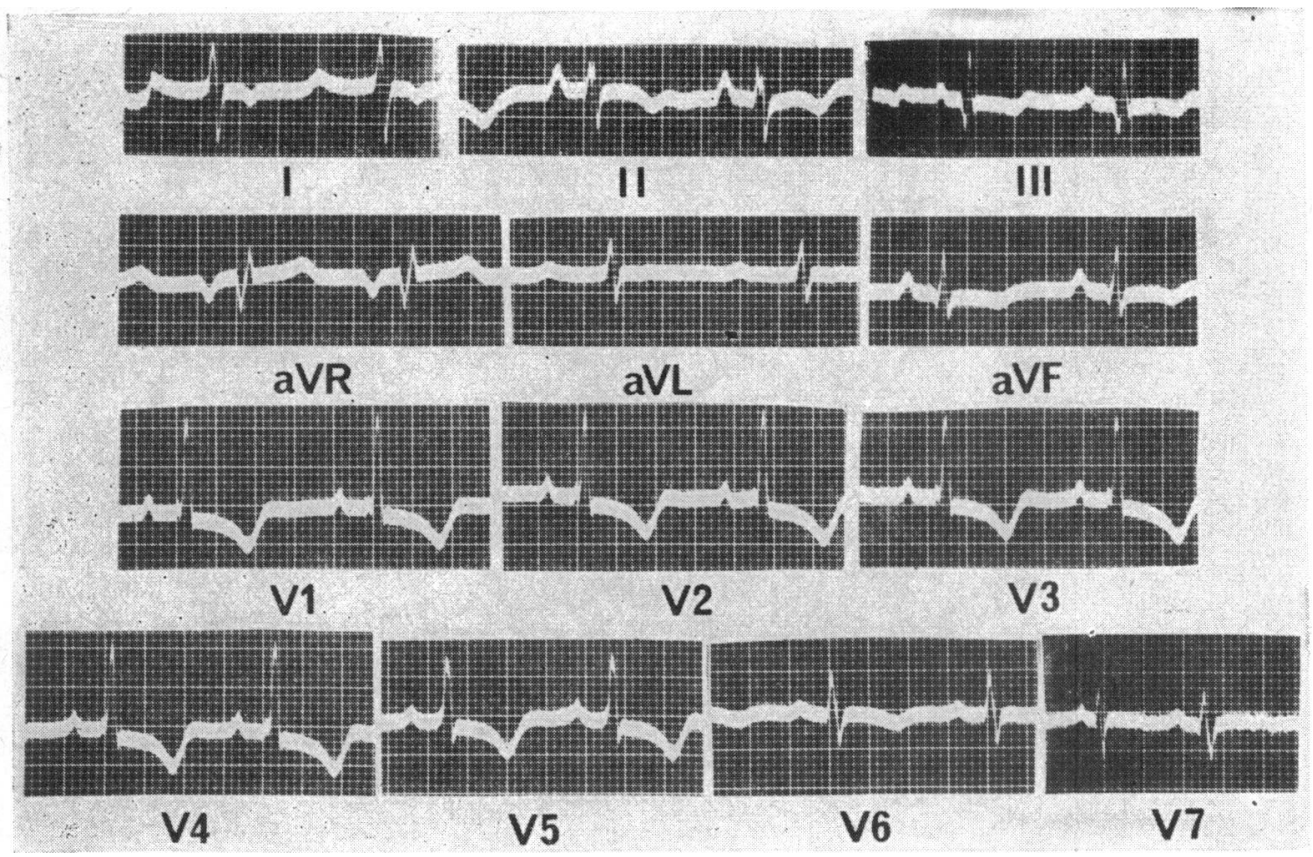

FIG. I Electrocardiogram of fune 1955, right ventricular preponderance.

but pushed over by a grossly enlarged right ventricle. Right atrial shadow increased, but not the left. Pulsation of ventricle and pulmonary artery exaggerated. Right hilar vessels show some enlargement but peripherally the calibre is small. The left hilum is obscured.'

Dr. M. Campbell kindly saw the patient and reported in 1955: 'The physical signs suggest pulmonary hypertension without any other cardiac lesion, and catheterization confirmed this and showed no other abnormality. There is, therefore, no question of surgical treatment. Pulmonary artery pressure is only 53 rising to 75 after exercise, and many patients stand a pressure well over I0O without getting these attacks. This made me search energetically for any other cause. Epilepsy was raised when he was a child but, as you will see from Dr. Mackenzie's report, there is nothing clinically to support this and nothing substantial in his E.E.G. I think there must be a large reflex and nervous side. Treatment should be limiting his activity, particularly any sudden start, and a long period of treatment with sedatives to try and reduce the ease with which this reflex can be precipitated.'

Course His exercise tolerance deteriorated progressively after the age of 24 , until he developed syncope even on walking 5 yards, and sometimes when he pulled up his blankets at night. Drugs, including sedatives and reserpine, gave no benefit. He died suddenly in October 1956, aged 25, when he walked to answer a telephone call.

Necropsy This was carried out by Dr. W. Lowi, and further pathological investigations by
Dr. G. L. Timms. There was great enlargement of the right ventricle and pulmonary artery and its main branches. There was a moderate degree of atheroma of the pulmonary artery. No evidence of thrombosis and no infarcts were found in the lungs.

Histology The pulmonary arterioles showed severe thickening from medial hypertrophy. There were no perivascular inflammatory changes. The capillaries in the alveolar walls were very dilated and there were angiomatoid lesions and some oedema (Fig. 3).

\section{Discussion}

Aetiology There are several possible causes of his pulmonary hypertension.

(I) Congenital defects in the media of small muscular arteries causing intimal proliferation over the deficiencies (Evans, Short, and Bedford, 1957). These authors found breathlessness the dominant symptom in their cases, but our patient did not suffer from this till his last few years.

(2) Repeated pulmonary emboli or thrombi cause many cases of 'primary' pulmonary hypertension (Friedberg, 1966). No such evidence could be found in our case, but increased platelet adhesiveness (Hirsh and McBride, 1965) or defective fibrinolysis (Ellison and Brown, 1965) were not excluded. Goodwin (1967) pointed out that pulmonary hypertension secondary to microembolism usually 


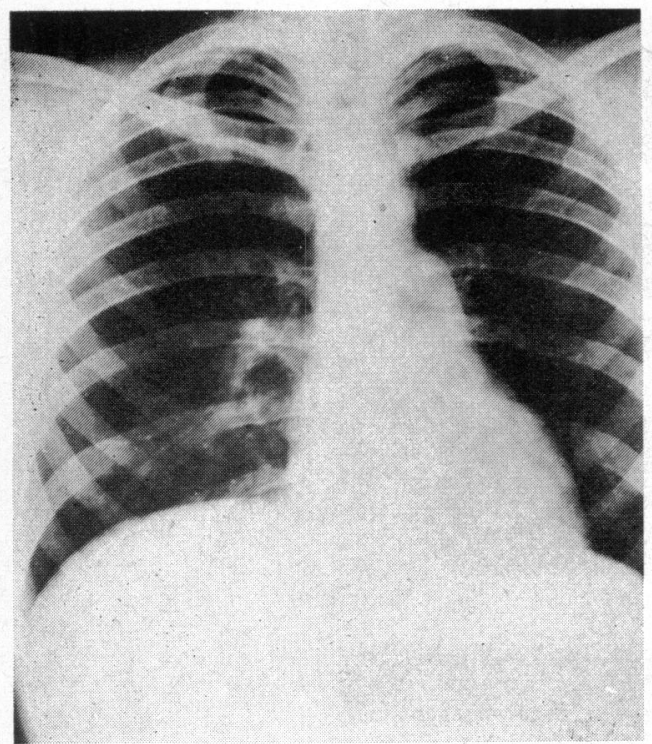

(a)

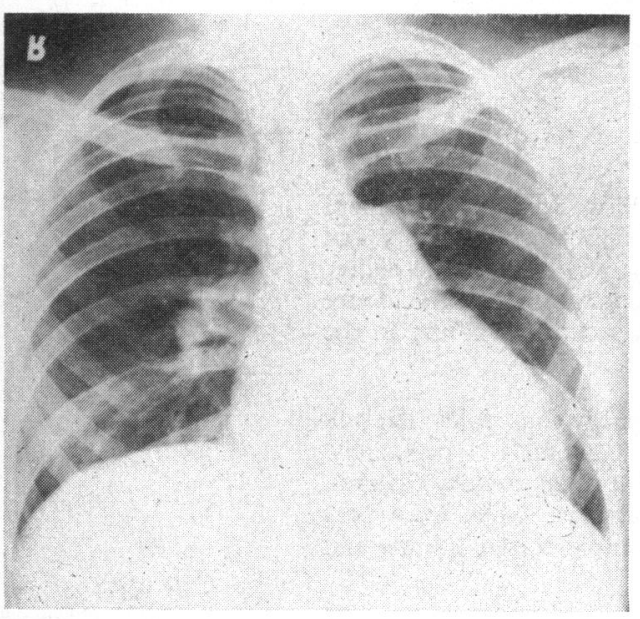

(b)

FIG. 2 Chest X-rays of 1953 and 1956, showing progressive right ventricular hypertrophy.

occurred in young women after a normal pregnancy.

(3) Allergic arteritis affecting lung vessels with subsequent thrombosis and organization. Berthrong and Cochran (1955) found evidence of pulmonary arteritis in 2 of their 9 cases and Wade (1954) suggested that the condition might be a connective tissue disorder characterized by fibrinoid change in 3 out of 5 cases. In our case there was no pathological evidence of arteritis, and the long course with normal health between episodes of syncope was against a collagen disease.

(4) Pulmonary hypertension may possibly

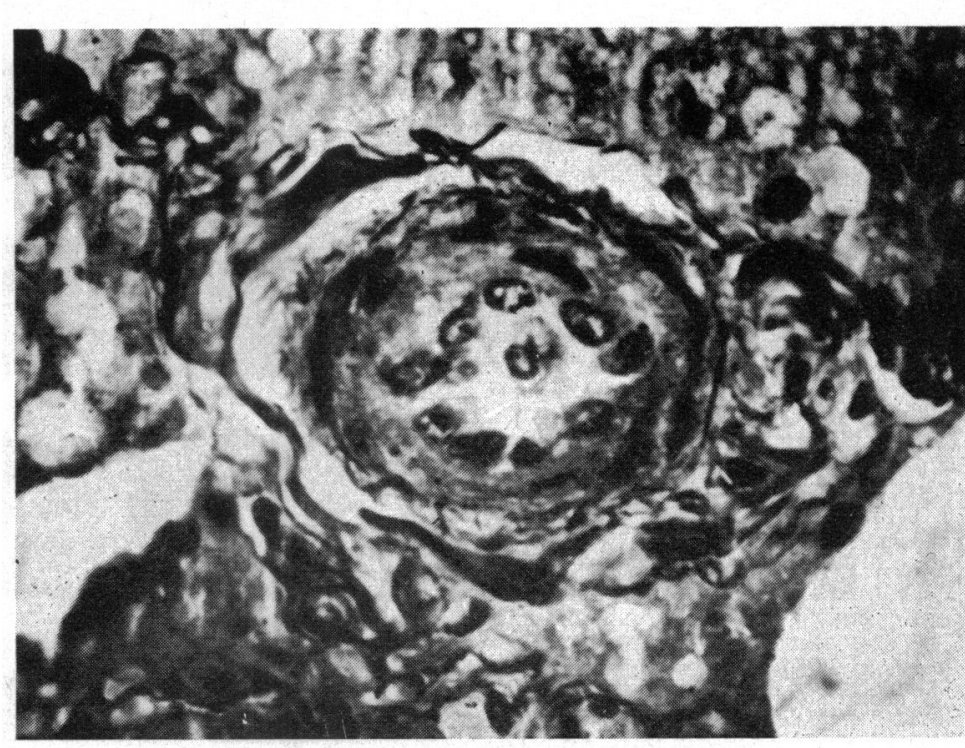

FI G. 3 Microphotograph of the lungs, showing medial hypertrophy of the pulmonary arterioles (see text).

result from excessive pulmonary vasomotor tone ( $\mathrm{Yu}, 1958)$. Shillingford (1967) indicated that primary changes in the pulmonary arteries might be responsible. Smith and Kroop (1957), Celoria, Friedell, and Sommers (1960), and Winters, Joseph, and Learner (1964) recorded an association of Raynaud's disease.

The most likely cause in our patient was a congenital anomaly. There was no family history in our patient, but otherwise his features would be compatible with this. A family history has been recorded by Fleming (1960) and by Coleman, Edmunds, and Tregillus (1959). Cases of 'primary' pulmonary hypertension in childhood have shown evidence of pulmonary vascular thrombosis, as in the 4 patients of Farrar, Reye, and Stuckey (196I) and the majority of the 9 of Berthrong and Cochran (1955). According to Heath and Edwards (1960), congenital pulmonary hypertension may be differentiated from the acquired variety by the persistence of a foetal configuration of the elastic tissue in the former.

Clinical features Our patient showed classical signs of severe pulmonary hypertension. His dominant symptom was syncope on effort. Howarth and Lowe (1953) attributed syncope in primary pulmonary hypertension to low cardiac output from acute right heart failure resulting from the steep rise of pulmonary artery pressure on exercise, but James (I962) thought it resulted from lesions in arteries supplying the sinus and AV nodes. 
Dressler (1952) invoked a reflex mechanism originating in neuroreceptors in the pulmonary artery with the vagus nerve as afferent pathway.

As suggested by Dr. Campbell, the disproportion between his syncope and the height of his pulmonary pressure indicated a large reflex factor, which would explain the long intervals of freedom from symptoms and the lack of constancy between the degree of exertion and his attacks. Possibly Dressler's theory of reflex mechanism may have had significance in this patient.

His pulmonary systolic pressure was 53 mm., rising to $75 \mathrm{~mm}$. after exercise, whereas the pressure was above $100 \mathrm{~mm}$. in the cases described by James (1962), Howarth and Lowe (1953), Dressler (1952), and Schafer et al. (1956), in 5 of 8 of Fleming's (1960), in 4 of Io of Chapman, Abbott, and Latson's (1957), in 3 of 6 of Yu's (1958) and in 7 of 16 of Sleeper, Orgain, and McIntosh's (1962), though it was labile in 2 cases in their early stages. Wood (1956), however, recorded pressures of approximately $100 \mathrm{~mm}$. or over in only 3 of his cases.

Course The average length of life from the onset of symptoms was 3.2 years in 20 cases recorded by Wood (1956). Maximum courses up to the time of death have been 9 years ( $\mathrm{Yu}$, 1958), ro years (Wood, 1956), and 13 years (Sleeper et al., 1962). We have not seen a previous record of a duration as long as 19 years, though Melmon and Braunwald (1963) reported 3 related patients who died 10, 12, and 18 years after the onset of their symptoms, the last dying accidentally.

We should like to record our sincere thanks to Dr. W. Lowi, who referred the patient and who arranged for the transport of the heart and lungs from Thomsons Falls to Nairobi; to Dr. G. L. Timms who arranged for the transfer of the organs from Nairobi to Australia; to Dr. R. R. Henderson, who also saw the patient, for his kind cooperation; to Professor R. E. J. ten Seldam for his expert opinion on the histological sections; and our gratitude to Dr. M. Campbell for his valuable advice and assistance in the preparation of this article.

\section{References}

Berthrong, M., and Cochran, T. H. (1955). Pathological findings in nine children with 'primary' pulmonary hypertension. Bulletin of the fohns Hopkins Hospital, 97, 69.

Celoria, G. C., Friedell, G. H., and Sommers, S. C. (1960). Raynaud's disease, and primary pulmonary hypertension. Circulation, 22, 1055.

Charman, D. W., Abbott, J. P., and Latson, J. (1957). Primary pulmonary hypertension. Review of literature and results of cardiac catheterization in ten patients. Circulation, 15, 35.
Coleman, P. N., Edmunds, A. W. B., and Tregillus, J. (1959). Primary pulmonary hypertension in three sibs. British Heart fournal, 21, 81.

Dressler, W. (1952). Effort syncope as an early manifestation of primary pulmonary hypertension. American fournal of the Medical Sciences, 223, 131.

Ellison, R. C., and Brown, J. (1965). Fibrinolysis in pulmonary vascular disease. Lancet, $1,786$.

Evans, W., Short, D. S., and Bedford, D. E. (1957). Solitary pulmonary hypertension. British Heart fournal, 19, 93.

Farrar, J. F., Reye, R. D. K., and Stuckey, D. (196I). Primary pulmonary hypertension in childhood. British Heart fournal, 23, 605.

Fleming, H. (1960). Primary pulmonary hypertension in eight patients including a mother and her daughter. Australasian Annals of Medicine, 9, 18.

Friedberg, C. K. (1966). Diseases of the Heart, 3rd ed., p. 1577. W. B. Saunders, Philadelphia and London.

Goodwin, J. F. (1967). In Clinicopathological Conference. A case of thromboembolic pulmonary hypertension, demonstrated at The Royal Postgraduate Medical School. British Medical fournal, 2, 624.

Heath, D., and Edwards, J. E. (1960). Configuration of elastic tissue of pulmonary trunk in idiopathic pulmonary hypertension. Circulation, 21, 59.

Hirsh, J., and McBride, J. A. (1965). Increased platelet adhesiveness in recurrent venous thrombosis and pulmonary embolism. British Medical fournal, 2, 797.

Howarth, S., and Lowe, J. B. (1953). The mechanism of effort syncope in primary pulmonary hypertension and cyanotic congenital heart disease. British Heart fournal, 15, 47.

James, T. N. (1962). On the cause of syncope and sudden death in primary pulmonary hypertension. Annals of Internal Medicine, 56, 252.

Melmon, K. L., and Braunwald, E. (1963). Familial pulmonary hypertension. New England fournal of Medicine, 269, 770.

Schafer, H., Blain, J. M., Ceballos, R., and Bing, R. J. (1956). Essential pulmonary hypertension: A report of clinical-physiologic studies in three patients, with death following catheterization of the heart. Annals of Internal Medicine, 44, 505.

Shillingford, J. P. (1967). In Clinicopathological Conference. A case of thromboembolic pulmonary hypertension, demonstrated at The Royal Postgraduate Medical School. British Medical fournal, 2, 624.

Sleeper, J. C., Orgain, E. S., and McIntosh, H. D. (1962). Primary pulmonary hypertension. Review of clinical features and pathologic physiology with a report of pulmonary hemodynamics derived from repeated catheterization. Circulation, 26, 1358.

Smith, W. M., and Kroop, I. G. (1957). Raynaud's disease in primary pulmonary hypertension. fournal of the American Medical Association, 165, 1245.

Wade, G. (1954). Clinical syndrome of primary pulmonary hypertension. The Association of Physicians of Great Britain and Ireland, 1954, Fortyeighth Annual General Meeting. Quarterly fournal of Medicine, 23, 456.

Winters, W. L., Joseph, R. R., and Learner, N. (1964). 'Primary' pulmonary hypertension and Raynaud's phenomenon. Case report and review of the literature. Archives of Internal Medicine, 114, 821.

Wood, P. (1956). Diseases of the Heart and Circulation, 2nd ed., pp. 84I and 846. Eyre \& Spottiswoode, London.

Yu, P. N. (1958). Primary pulmonary hypertension: Report of six cases and review of literature. Annals of Internal Medicine, 49, 1138. 